\title{
Possible cytokine biomarkers in pediatric acute appendicitis
}

\author{
Nikola Stankovic ${ }^{1,2^{*}}$ D, Maja Surbatovic ${ }^{3,4}$, Ivan Stanojevic ${ }^{3,4}$, Radoje Simic $i^{1,2}$, Slavisa Djuricic ${ }^{1,5}$, Maja Milickovic ${ }^{1,2}$, \\ Blagoje Grujic ${ }^{1,2}$, Djordje Savic ${ }^{1,2}$, Vesna Milojkovic Marinovic ${ }^{1,2}$, Miona Stankovic ${ }^{6}$ and Danilo Vojvodic ${ }^{3,4}$
}

\begin{abstract}
Background: Diagnosis of acute appendicitis (AA) and decisions about its treatment remain among the most common dilemmas of pediatric surgical teams. Monitoring of immune response may be of importance for this purpose. Our aim was to measure and analyze serum and peritoneal fluid cytokines, in children who had undergone surgery for suspected AA.
\end{abstract}

Methods: Prospective investigation of serum and peritoneal fluid cytokine values was performed in 127 consecutive patients. According to the pathohistological findings, patients were divided into three groups: normal/ early, uncomplicated and complicated AA. Determination of cytokine concentrations for 20 different cytokines was done using a commercial flow cytometry kit: Human Inflammation 20 plex BMS 819.

Results: Statistically significant differences in serum cytokine values between pathohistological groups were found for IP-10, MIP-1a and IL-10. Preoperative cut-off values of IP-10, MIP-1a and IL-10 between groups were obtained using ROC curve analysis. Positive correlations between serum and peritoneal concentrations were recorded for most of the analyzed cytokines.

Conclusion: IP-10, MIP-1a and IL-10 showed potential in assessment of AA in children. Confirmatory studies with a larger number of patients are required to prove reliability of these biomarkers.

Keywords: Biomarker, Cytokine, Acute appendicitis, Children

\section{Introduction}

There is no clear guidance to drive a clinical decision between conservative and surgical treatment of acute appendicitis (AA) in children. This results in significant number of unnecessary surgeries [1] or appendiceal perforations, classifying AA as one of the most frequently misdiagnosed conditions in pediatric surgery. Contributing factors include poor clinical history, insufficient cooperation during physical examination, and the medical team's fear of perforative appendicitis risk [2].

Introduction of imaging methods has improved diagnostics, but without the desired reduction in negative appendectomy rate [1,3] and complicated forms of appendicitis [4]. Ultrasonography usually gives insufficient information, while computerized tomography is linked

\footnotetext{
* Correspondence: kokanasta@gmail.com

${ }^{1}$ Mother And Child Health Care Institute of Serbia, Radoja Dakica 6, Belgrade 11000, Serbia

${ }^{2}$ Faculty of Medicine, University of Belgrade, Belgrade, Serbia

Full list of author information is available at the end of the article
}

to high doses of ionizing radiation, and its use is therefore questionable in terms of benefit versus risk.

Standard laboratory parameters such as white blood count (WBC) with leukocyte formula and C-reactive protein (CRP) are not specific and sensitive enough for diagnosis of AA [5]. New laboratory technologies and the development of immunology improve monitoring of inflammatory processes, and allow searching for specific biomarkers in order to optimize diagnosis of AA [6-8].

Inflammation in AA includes activation of immune cells, and their complex interaction is mediated by a number of cytokines. Cytokines are predominantly secreted by macrophage cells and T-lymphocytes, and this large group of proteins, peptides, or glycoproteins can be classified as pro-inflammatory or anti-inflammatory according to their function in immune response.

So far, investigations involving measurement of cytokines in AA have been conducted predominantly in

(c) The Author(s). 2019 Open Access This article is distributed under the terms of the Creative Commons Attribution 4.0 International License (http://creativecommons.org/licenses/by/4.0/), which permits unrestricted use, distribution, and reproduction in any medium, provided you give appropriate credit to the original author(s) and the source, provide a link to the Creative Commons license, and indicate if changes were made. The Creative Commons Public Domain Dedication waiver (http://creativecommons.org/publicdomain/zero/1.0/) applies to the data made available in this article, unless otherwise stated. 
adults [9-11], with only a small number in pediatric patients $[12,13]$.

In this prospective trial, we analyzed serum and peritoneal cytokine concentrations in children referred for surgery due to suspected AA, with the aim of identifying mediators that could improve diagnosis of AA in children.

\section{Patients and methods}

During the period April-December 2015, patients admitted to the Mother and Child Healthcare Institute of Serbia with a clinical diagnosis of AA requiring open surgery were eligible for prospective evaluation within this trial. The following population was not eligible: children under 3 years or older than 16 years; patients with other acute diseases; patients with an operative finding of other abdominal inflammation; and patients referred for laparoscopic surgery. Informed consent from a parent or legal guardian was obtained for all patients included in this trial. The trial was approved by an Institutional Ethics Committee, and run in line with Good Clinical Practice and the Declaration of Helsinki.

A total of 127 patients were stratified into three groups, according to pathohistological findings. The first group comprised patients with a normal appendix or early stage appendicitis (NEAA), where a normal appendix was found. The second group comprised patients with phlegmonous or uncomplicated appendicitis (UAA). The third group comprised patients with gangrenous and/or perforated appendicitis, classed as complicated appendicitis (CAA).

Baseline evaluation was done on the day of surgery, and included blood and peritoneal fluid sampling. Serum obtained by peripheral venous blood centrifugation was taken before surgery, and supernatant obtained by centrifugation of peritoneal fluid was taken just after laparotomy; both were stored at $-70 \mathrm{C}$ for later measurement of cytokines. Two additional blood samplings were performed at the 1st and the 3rd postoperative day for the same laboratory analysis. All resection samples obtained were sent for histological processing.

Determination of the cytokine concentrations in the sera and peritoneal fluid supernatants was performed on a Beckman Coulter FC500 cytometer, according to the manufacturer's instructions of the commercial flow cytometry kit: Human Inflammation 20 plex BMS 819. It contains reactants for determination of the following cytokines: sE-selectin, G-CSF, ICAM-1, IFN- $\alpha$, IFN- $\gamma$, IL- $1 \alpha$, IL-1 $\beta$, IL-4, IL-6, IL-8, IL-10, IL-12p70, IL-13, IL-17A, IP10, MCP-1, MIP- $1 \alpha$, MIP- $1 \beta$, LAP and TNF- $\alpha$.

PRISM GraphPad software version 5.01 was used for statistical analysis. Correlations (Spearman rho) and comparisons (Mann-Whitney U-test) were calculated for comparative statistics (z-score and two-tailed P).

The study was approved by the Ethics Committee of the Mother and Child Healthcare Institute of Serbia, and run in line with Good Clinical Practice and the Declaration of Helsinki.

\section{Results}

There were 77 male and 50 female patients from 3 to 16 years old (on average $10.43 \pm 4.02$ ), distributed as shown in Table 1.

The accuracy of surgeons' intraoperative diagnosis (percentage of pathohistologicaly confirmed intraoperative findings) was $73.2 \%$, while the incidence of negative appendectomy (absence of inflammation in the appendix after surgical intervention for suspected appendicitis) was $15.7 \%$.

\section{Preoperative differences of serum cytokine values between pathohistological groups}

Statistically significant differences between preoperative serum cytokine values of the pathohistological groups were found for IP-10, MIP-1 $\alpha$ and IL-10 (Fig. 1). The other 17 examined cytokines did not show a statistically significant difference preoperatively (not shown).

In the preoperative samples, the highest values of IP-10 were found in NEAA, while the lowest were recorded in CAA group (Fig. 1 A). Values of IP-10 in the NEAA group were significantly higher than values in UAA $(31,962 \pm 54$, 209 vs. $8437 \pm 17,431, p=0.0410$ ) and CAA group (31, $962 \pm 54,209$ vs. $3099 \pm 4771, p=0.0099)$. Statistical significance was not reached in comparison of the preoperative IP-10 values between the UAA and CAA groups.

MIP- $1 \alpha$ had the highest preoperative values in CAA, and the lowest in UAA (Fig. 1 B). Significant statistical

Table 1 Demographic characteristics and distribution within groups (NEAA - normal or early acute appendicitis; UAA uncomplicated acute appendicitis; CAA - complicated acute appendicitis)

\begin{tabular}{|c|c|c|c|c|c|c|c|c|}
\hline & \multicolumn{2}{|c|}{$3-8$ years old } & \multicolumn{2}{|c|}{ 9-12 years old } & \multicolumn{2}{|c|}{$13-16$ years old } & \multicolumn{2}{|l|}{ total } \\
\hline & boys & girls & boys & girls & boys & girls & boys & girls \\
\hline $\operatorname{NEAA}(n=20)$ & 5 & 3 & 2 & 2 & 2 & 6 & 9 & 11 \\
\hline UAA $(n=30)$ & 4 & 6 & 8 & 1 & 6 & 5 & 18 & 12 \\
\hline CAA $(n=77)$ & 22 & 8 & 12 & 9 & 16 & 10 & 50 & 27 \\
\hline \multirow[t]{2}{*}{ total } & 31 & 17 & 22 & 12 & 24 & 21 & 77 & 50 \\
\hline & 48 & & 34 & & 45 & & 127 & \\
\hline
\end{tabular}




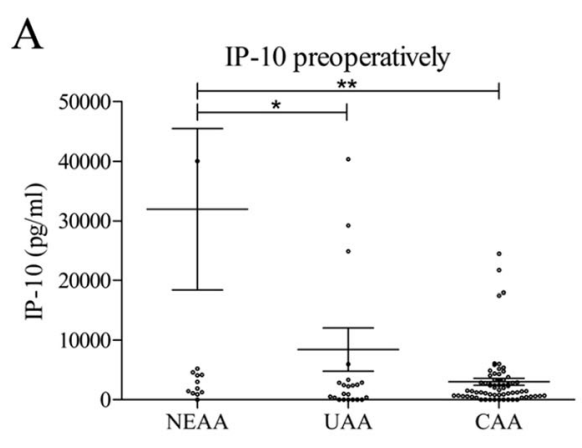

B

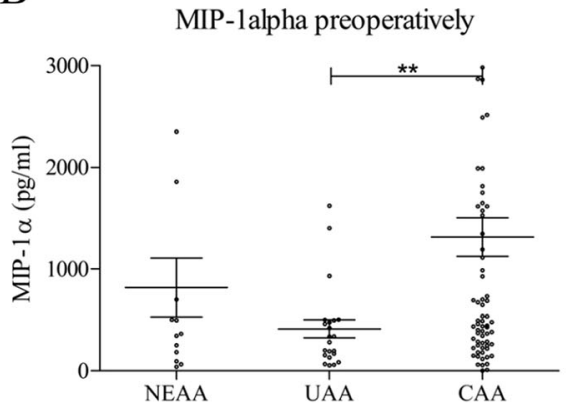

$\mathrm{C}$

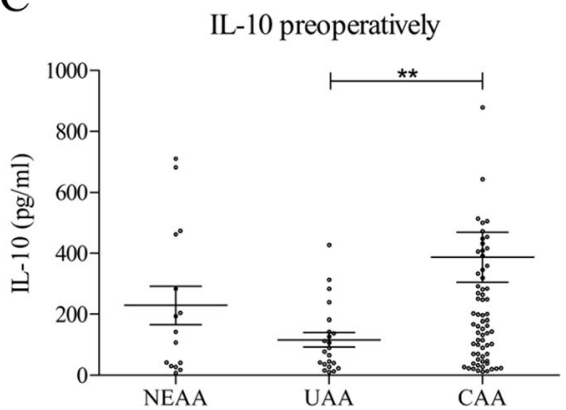

Fig. 1 Preoperative comparison of serum cytokine values between pathohistological groups: IP-10 (a); MIP-1a (b); IL-10 (c). NEAA - normal or early acute appendicitis; UAA - uncomplicated acute appendicitis; CAA - complicated acute appendicitis. [mean \pm standard error of mean (SEM), Mann-Withney test, $\left.{ }^{*} p<0.05,{ }^{* *} p<0.01,{ }^{* * *} p<0.001\right]$

difference was recorded only between the UAA and CAA groups $(412 \pm 414$ vs. $1113 \pm 1618, p=0.0065)$.

Preoperative IL-10 values were the highest in CAA, and the lowest in UAA (Fig. $1 \mathrm{C}$ ), showing significant statistical difference $(116 \pm 111$ vs. $386 \pm 695, p=$ $0.0079)$, while significant differences were not found in comparisons of these two groups with the NEAA group.

\section{IP-10, MIP-1a and IL-10 cut-off values between pathohistological groups}

The optimal cut-off value of IP-10 between the NEAA and UAA groups was $2956 \mathrm{pg} / \mathrm{ml}$, with sensitivity of $73.91 \%$ and specificity of $62.5 \%$ (AUC = $0.7090, p=0.009742$; Fig. 2 A). For the NEAA and CAA groups, the optimal IP-10 cutoff value was $2994 \mathrm{pg} / \mathrm{ml}$, with sensitivity of $73.13 \%$ and specificity of $62.5 \%$ (AUC $=0.6957, p=0.03986$; Fig. 2 B). The optimal cutoff value of IP-10 between the NEAA and IAA (inflamed acute appendix; UAA + CAA) groups was also $2994 \mathrm{pg} / \mathrm{ml}$, with sensitivity of $73.53 \%$ and specificity of $62.18 \%(\mathrm{AUC}=0.8175, p<$ 0.0001; Fig. 2 C).

In the case of MIP- $1 \alpha$, the optimal cut-off value between the UAA and CAA groups was $424 \mathrm{pg} / \mathrm{ml}$, with sensitivity of $61.11 \%$ and specificity of $63.64 \%$ (AUC = 0.6926, $p=0.006479$; Fig. 2 D).
Optimal cut-off value of IL-10 between the UAA and CAA groups was $130 \mathrm{pg} / \mathrm{ml}$, with sensitivity of 62.50 and specificity of $68.18 \mathrm{pg} / \mathrm{ml} \quad(\mathrm{AUC}=0.6881, p=0.007813$, Fig. 2 E) .

All five conducted tests could be considered as tests with moderate accuracy.

\section{Differences in serum cytokine values between} pathohistological groups on the 1st postoperative day On the first postoperative day, a difference in cytokine values between pathohistological groups was recorded only in the case of IP-10, with the highest values in NEAA and the lowest in UAA (Fig. 3). These values discriminated between the three pathohistological groups. Values in the NEAA group were significantly higher than in UAA $(31,404 \pm 38,365$ vs. $3868 \pm 11,810, p=$ $0.0049)$ or in CAA $(31,404 \pm 38,365$ vs. $11,658 \pm 27,013$, $p=0.0281)$. Similarly, statistically significant difference was found between UAA and CAA (3868 $\pm 11,810$ vs. $11,658 \pm 27,013, p=0.0364)$. The other 19 examined $c y-$ tokines did not show a statistically significant difference on the first postoperative day (not shown).

\section{Differences in serum cytokine values between} pathohistological groups on the 3rd postoperative day On the third postoperative day, significant differences between groups in serum cytokine concentrations were found 
A

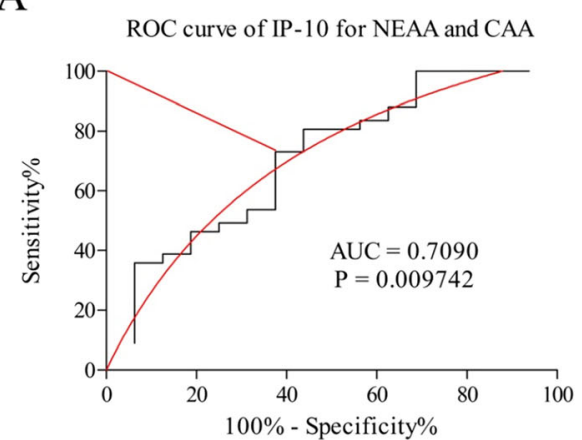

B

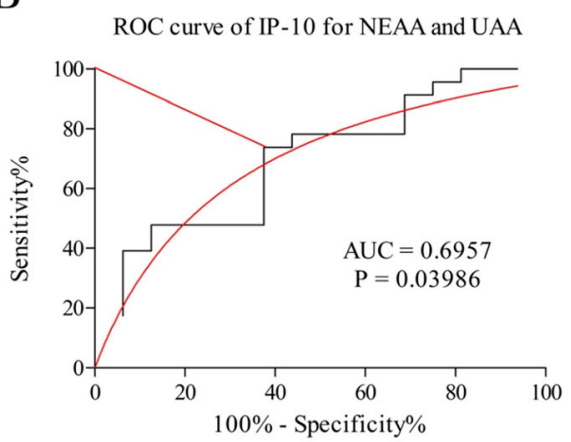

C

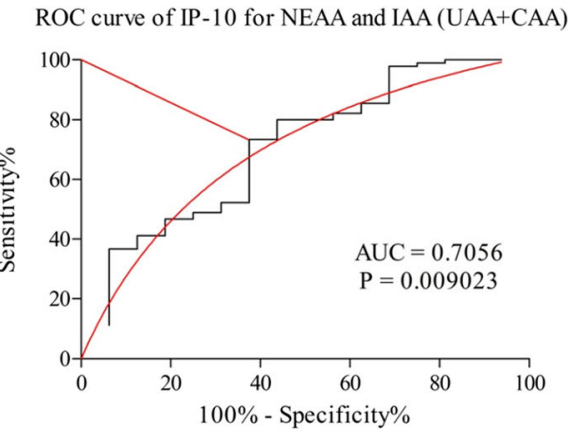

D

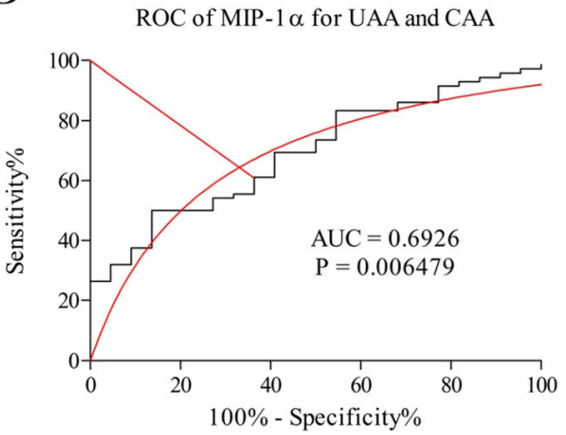

E

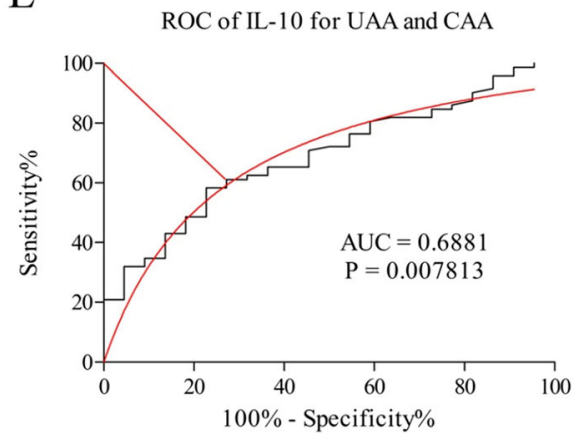

Fig. 2 ROC (Receiver Operating Characteristic) curves of cytokines for formed pathohistological groups. NEAA - normal or early acute appendicitis; UAA - uncomplicated acute appendicitis; CAA - complicated acute appendicitis; IAA - inflamed acute appendicitis. ROC curve of IP10 for NEAA and UAA (a); ROC curve IP-10 for NEAA and CAA (b); ROC curve of IP-10 for NEAA and IAA (UAA + CAA) (c); ROC curve of MIP-1a for UAA and CAA (d); ROC curve of IL-10 for UAA and CAA (e)

only for IL-10 and MIP-1 $\alpha$ (Fig. 4). The other 18 examined cytokines did not show a statistically significant difference (not shown).

Concentrations of IL-10 were highest in NEAA and lowest in UAA (Fig. 4 A). Values in UAA were significantly lower compared to CAA ( $236 \pm 362$ vs. $508 \pm 834$, $p=0.0430)$, but not compared to NEAA. Statistically significant differences were not found between the NEAA and UAA values.

MIP- $1 \alpha$ values showed similar relations between groups as IL-10 values (Fig. 4B). Significant difference was recorded only between UAA and CAA $(619 \pm 557$ vs. $1779 \pm 2869, p=0.0352$ ).

\section{Preoperative correlations of serum and peritoneal cytokine values in the total population}

Preoperative serum and peritoneal concentrations showed strong positive correlations for IP-10 (Spearman $r=0.4275$, $p<0.0001$, Fig. 5 A), MIP-1 $\alpha$ (Spearman $\mathrm{r}=0.5386, \mathrm{p}<$ 0.0001, Fig. 5 B) and IL-10 (Spearman $r=0.4573, p<0.0001$, Fig. 5 C). All other investigated mediators in this study, with exception of IL-6, also demonstrated positive correlation between their serum and peritoneal values (not shown).

\section{Discussion}

Reliability in diagnosis of AA is improved by combining clinical and imaging methods with WBC and CRP values, 


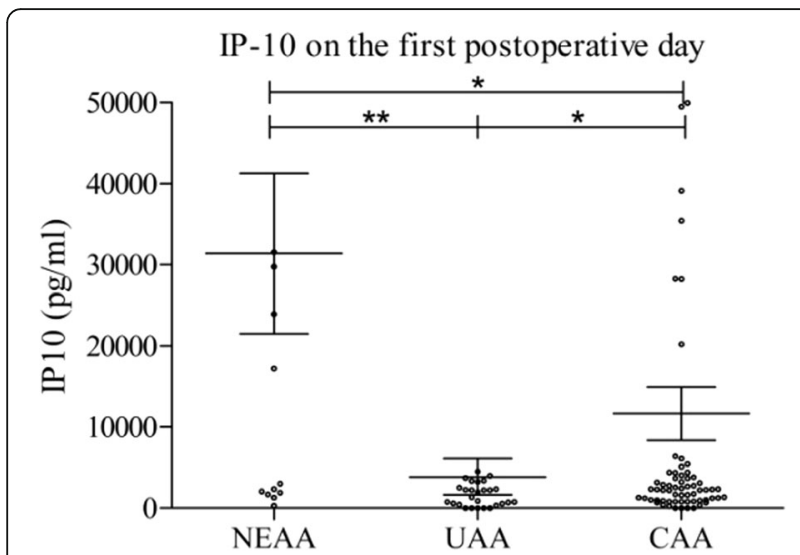

Fig. 3 Comparison of IP-10 values between pathohistological groups on the first postoperative day. NEAA - normal or early acute appendicitis; UAA - uncomplicated acute appendicitis; CAA complicated acute appendicitis. [mean \pm standard error of mean (SEM), Mann-Withney test, ${ }^{*} p<0.05,{ }^{* *} p<0.01,{ }^{* * *} p<0.001$ ]

which are the laboratory gold standard. As imaging methods are time consuming and may involve exposure to radiation, and echosonography is usually insufficiently informative [14]. A combination of physical examination and laboratory tests therefore remains the gold standard, although no laboratory parameters show sufficient sensitivity and specificity $[5,15]$. For instance, acute mesenteric lymphadenitis has the most similar clinical presentation to AA.

Neutrophils represent one of the first lines of defense against penetrating agents. These phagocytes secrete lytic enzymes and produce free oxygen radicals with high antimicrobial potential. Their activation is triggered by bacteria, and by secreted cytokines and chemokines. The number of neutrophils in the blood grows by mobilization of marginal pool and bone marrow, in proportion to the extent of inflammation. Lymphocytes are immunocompetent cells that coordinate immune response and assist in neutrophil activation. CRP is an acute inflamatory phase reactant synthesized in the liver under control of IL-6. Along with positive physical and radiological findings, it may have good diagnostic value in AA. However, as an isolated parameter it is not useful, because of low specificity [5]. On the other hand, the first increase in CRP occurs $12 \mathrm{~h}$ after inflammation starts, with peak plasma concentration between 24 to 48 hours [16]. Some studies suggest that CRP is an important diagnostic agent for perforated AA but not for AA in general [17].

Laboratory parameters which include the value of neutrophils, such as absolute neutrophil count, percentage of neutrophils in the leukocyte formula, and neutrophilto-lymphocyte ratio (NLR), are considered as a better diagnostic agent in AA, because neutrophils rise faster than CRP which needs time for synthesis in the liver [18]. Some studies showed that NLR appears to have greater diagnostic accuracy than WBC [19]. In our previous publication we confirmed a faster activation of neutrophils and NLR increase, and delayed increase of CRP, in pediatric AA [20, 21]. Therefore usefulness of NLR in early diagnosis of AA is superior to CRP, but still not sufficiently reliable. In the gangrenous form of AA, significant lymphopenia may be described whose pathophysiological mechanism is not fully understood $[22,23]$. In accordance with this, the increase in the value of NLR in developed form of AA occurs as a result of the increase in the number of neutrophils as well as in reduction of the number of lymphocytes.

Monitoring of immune response and cytokine profiles may be of importance in the diagnosis of AA. Identifying highly specific biomarkers for certain stages of AA would make clinical decisions much easier. Similarly to our study, other investigations have aimed to identify potential biomarker functions of serum cytokines, in order to determine the presence or absence of the inflammatory process and the degree of inflammation in the appendix [24-26]. The clinical significance of these potential serum biomarkers could include: reducing the number of negative appendectomies, better assessment of treatment, choice of antibiotic therapy and surgical
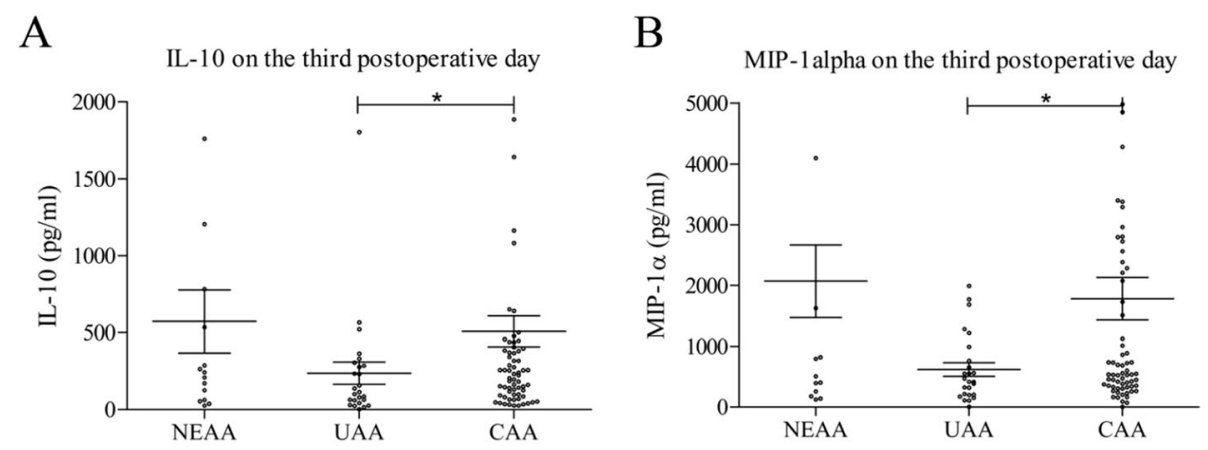

Fig. 4 Comparison of cytokine values between pathohistological groups on the third postoperative day: IL-10 (a); MIP-1a (b). NEAA - normal or early acute appendicitis; UAA - uncomplicated acute appendicitis; CAA - complicated acute appendicitis. [mean \pm standard error of mean (SEM), Mann-Withney test, ${ }^{*} p<0.05,{ }^{* *} p<0.01$, ${ }^{* * *} p<0.001$ ] 
A
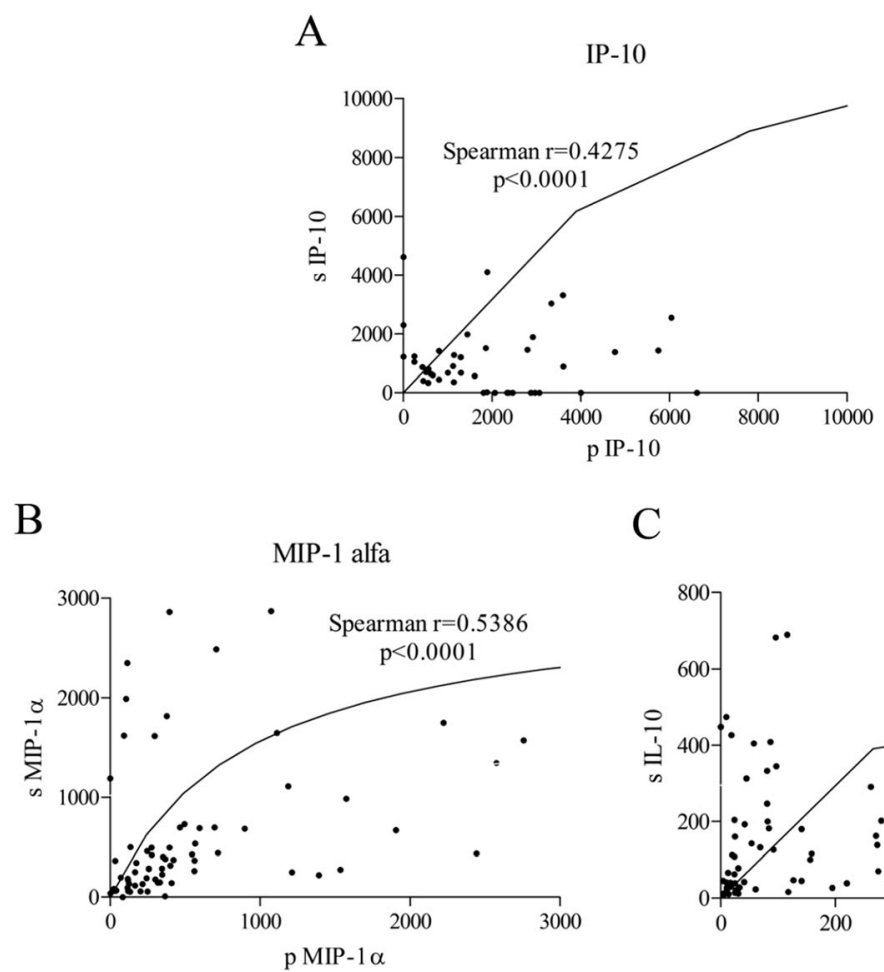

$\mathrm{C}$

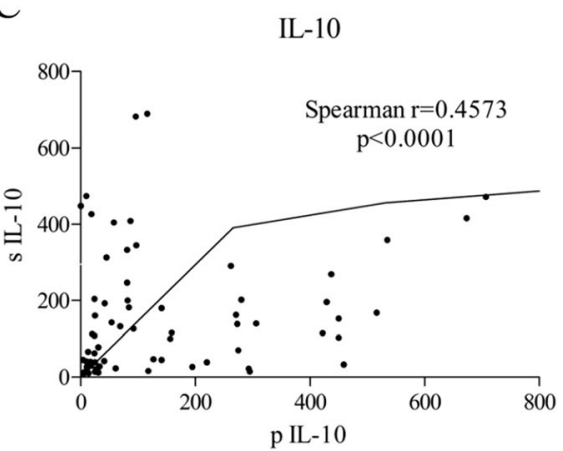

Fig. 5 Correlation of preoperative serum and peritoneal cytokine values on total patients: IP-10 (a); MIP-1a (b); IL-10 (c)

techniques, better planning of recovery, and reduced overall hospital costs. However, based on current knowledge, there is no reliable biomarker with the above characteristics [14]. Even though other studies have explored this problem, none of them used the comprehensive set of 20 different cytokines (determined by Human Inflammation 20 plex BMS 819) for sample testing, as was done within this trial.

Yoon et al. evaluated five cytokine molecules, including pro-inflammatory IL-1 $\beta$, IL-6 and IL-8, IL-2 and antiinflammatory IL-10 [27]. The results suggested the importance of IL- 6 and IL-8 in the differentiation of perforative and non-perforative acute appendicitis. Although in our patients, concentrations of these cytokines in serum were elevated, especially in the CAA group, the difference was not significant and their differential potential was not confirmed. In another study with mixed age groups of patients, the usefulness of IL-10 for this purpose was presented [8], confirming the conclusions of several previous studies [28-30].

The results of this trial identify 3 out of 20 tested serum cytokines, IL-10, MIP-1 $\alpha$ and IP-10, which showed statistically different concentrations between pathohistological groups.

Interleukin 10 (IL-10) is an anti-inflammatory cytokine primarily produced by activated macrophages and Th2cells. Its role is to reduce antigen-presenting capacity of cells and to inhibit Th1 immune response. At the same time, IL-10 potentiates Th2 response, enhancing the proliferation of B-cells and synthesis of antibodies [31]. According to the findings of this study, IL-10 was the only interleukin whose level varied significantly between UAA and CAA. Pre-operative serum levels of IL-10 were significantly higher in CAA, which can be explained by enhanced Th2 activity in the developed form of AA.

Macrophage inflammatory protein $1 \alpha$ (MIP-1 $\alpha)$ belongs to a family of chemokines primarily produced by macrophage cells activated by bacterial endotoxin, and has a crucial role in immune response to infection [32]. The pro-inflammatory role of this cytokine is reflected in the activation of granulocytes, and the induction of synthesis of other pro-inflammatory cytokines. Results of this study show that values of MIP- $1 \alpha$ differentiated UAA and CAA in a similar manner as IL-10. This chemokine plays significant role in attraction and activation of granulocytes, and its serum concentration was expectedly higher in advanced AA. These are the first published results of MIP- $1 \alpha$ monitoring in AA.

Interferon inducible protein 10 (IP-10) is a chemokine secreted by many cells stimulated by IFN- $\gamma$, such as monocytes, fibroblasts and endothelial cells. The biological function of IP-10 is attraction of mononuclear phagocytes and promotion of Th1 immune response [33, 34]. Its activity is directly correlated to Th1 response, and accordingly its serum concentrations may be of value in monitoring of 
immune processes [35]. Results of this trial demonstrate that serum concentrations of IP-10 could distinguish NEAA from the other two groups, but could not distinguish between UAA and CAA. As expected, when we correlated serum levels of IP-10 with levels of IFN- $\gamma$, which is a well-known inducer of IP-10, we found strong positive correlation in the UAA and CAA groups $(p=0.0003$, Spearman $\mathrm{r}=0.6801$ and $p<0.0001$ Spearman $\mathrm{r}=0.6500$, respectively, not shown). In contrast, in the NEAA patient group, which otherwise showed statistically highest IP-10 values, there was no statistically significant correlation of IP-10 with IFN- $\gamma$. In addition, the IFN- $\gamma$ levels showed no statistically significant differences between the NEAA, UAA and CAA groups. Taken together, these findings indicate the possibility that the prompt upregulation of IP-10 in the NEAA patient group could be achieved by mechanisms other than IFN- $\gamma$ mediated induction. Interpretations of IP10 levels in AA have rarely been published.

The triple biomarker set we describe, composed of one anti-inflammatory cytokine and two chemokines, could be useful in clinical assessment of AA in children, as an "add-on" diagnostic test to other standard diagnostic tools for AA. IP-10 assessment can be used in order to confirm exclusion of AA, while IL-10 and MIP- $1 \alpha$ can be tools for differentiation between uncomplicated and complicated AA. Cutoff values obtained by ROC curve analysis in this trial were classified as tests with poor to moderate reliability. However, a study with a larger and more uniform patient group could provide better reliability.

The accuracy of surgeons' intraoperative diagnosis was $73.2 \%$ within the setting of this trial, and this is similar to other published results [36]. The largest discrepancy between intraoperative and histological findings was in the case of perforative appendicitis. This is likely due to micro perforations, which are not visible macroscopically during the surgery. These specimens are sent to the pathologist with an intraoperative diagnosis of uncomplicated appendicitis, but micro perforations are detected later by microscope, leading to classification as a complicated form of AA.

The incidence of negative appendectomy was $15.7 \%$, which is significantly lower than previously published results in adult and pediatric patients [37, 38].

Evaluation of cytokine serum concentration after surgery could serve for monitoring of recovery and potential development of complications. According to Eriksson et al., reliable estimation of complications could be based on monitoring of leukocytes, CRP and IL-6 [39]. The only cytokine that separated groups on the first postoperative day in this study was IP-10. On the third postoperative day, concentrations of IL- 10 and MIP- $1 \alpha$ were able to separate UAA and CAA, but not NEAA from these two groups. Thus, in the three-day postoperative period of the study, the same cytokine variables could distinguish between diagnostic groups. A few studies have evaluated IL10 after surgery for AA $[8,13,40,41]$, but there is no available data for MIP- $1 \alpha$ and IP-10.

In this study, analysis of peritoneal cytokine concentrations was done in peritoneal fluid samples taken at the beginning of surgery, immediately after the peritoneal cavity had been opened. Single peritoneal fluid sampling allowed analysis of group differentiation but not analysis of post-operative cytokine value changes, as had been the case for blood sampling for serum cytokines. Separation of groups on the basis of peritoneal cytokine concentrations is well described. Local processes within AA can have be reflected systemically with variable intensity. It can be completely restricted, and thus without systemic effects and corresponding serum changes, or can be transmitted to a systemic level to a lesser or greater extent. The effects of pro-inflammatory cytokines can be transmitted to a systemic level, increasing the risk of an inflammatory reaction in previously intact organs and tissues [42-44]. Conversely, locally created pro-inflammatory cytokines can induce suppression of systemic inflammation and prevent inflammation in other tissues [45-48].

Although a large number of investigations were conducted to qualify and quantify local and systemic immune response, and to determine the pro- or antiinflammatory character of response in AA, this study was aimed to evaluate and differentiate stages of AA and potential clinical benefit in diagnosis and follow up of children with AA. Peritoneal cytokine concentrations are more likely than serum concentrations to differentiate pathohistological groups, even if peritoneal samples are impossible to obtain before a surgical procedure.

There is significant positive correlation between serum and peritoneal cytokine values for most of the tested cytokines. However, only 3 out of 20 cytokines from this investigation showed sufficient differences in serum values to differentiate among described groups of patients.

The main limitation of this study is imbalance between pathohistological groups, especially the numerical domination of patients with complicated AA. Cytokine kinetics and the half-life of certain cytokines in plasma, as well as differences between their in vivo and in vitro activities, can be considered as other potential limiting factors.

\section{Conclusion}

The surgeon's clinical examination remains the most important factor in the diagnosis of AA in children. The possibility of distinguishing preoperatively between different stages of AA in children, based on serum cytokine levels, would be of great value in clinical practice. According to the results of this study, IL-10, MIP- $1 \alpha$ and 
IP-10 showed potential to help achieve this goal. In conjunction with clinical examination, standard laboratory tests and ultrasound, these parameters could help clinicians in evaluation and decision-making in their therapeutic approach for suspected AA. However, so far these cytokines have not been sufficiently examined in preoperative and postoperative laboratory monitoring of AA.

Confirmatory studies with a larger number of patients are required to prove reliability of these biomarkers in diagnosis and follow up of AA in children.

\section{Acknowledgements}

The authors are grateful to parents, children and health professionals who participated in the study.

\section{Authors' contributions}

NS, MSu, IS and DV designed the study. NS designed and wrote the manuscript. MM, BG and VMM collected specimens and data. SD, and RS analyzed data. MSu, MSt, DV and DS reviewed the manuscript. All authors read and approved the final version of the manuscript.

\section{Funding}

Not applicable.

\section{Availability of data and materials}

The datasets used and/or analysed during the current study are available from the corresponding author on reasonable request.

\section{Ethics approval and consent to participate}

The study was approved by the Ethics Committee of the Mother and Child Healthcare Institute of Serbia. Informed consent was obtained from parents after detailed explanation of the purpose of the study. Parents were told they would have the right to withdraw from the study at any time during the interview.

\section{Consent for publication}

The parents of patients give informed consent for publication of the results of this study.

\section{Competing interests}

The authors declare that they have no competing interest.

\section{Author details}

${ }^{1}$ Mother And Child Health Care Institute of Serbia, Radoja Dakica 6, Belgrade 11000, Serbia. ${ }^{2}$ Faculty of Medicine, University of Belgrade, Belgrade, Serbia. ${ }^{3}$ Military Medical Academy, Belgrade, Serbia. ${ }^{4}$ Faculty of Medicine of the Military Medical Academy, University of Defence, Belgrade, Serbia. ${ }^{5}$ Banjaluka University School of Medicine, Banjaluka, Bosnia and Herzegovina. ${ }^{6}$ Novartis, Serbia.

Received: 12 June 2019 Accepted: 30 September 2019

Published online: 15 October 2019

\section{References}

1. Kaiser S, Frenckner B, Jorulf HK. Suspected appendicitis in children: US and CT: a prospective randomized study. Radiology. 2002;223:633-8.

2. Flum DR, Morris A, Koepsell T, Dellinger EP. Has misdiagnosis of appendicitis decreased over time? A population-based analysis. JAMA. 2001;286:1748-53.

3. Somekh E, Serour F, Gorenstein A, Vohl M, Lehman D. Phenotypic pattern of $B$ cells in the appendix: reduced intensity of CD 19 expression. Immunobiology. 2000;201:461-9.

4. OToole SJ, Karamanoukian HL, Allen JE, et al. Insurance-related differences in the presentation of pediatric appendicitis. J Pediatr Surg. 1996:31:1032-4.

5. Yu CW, Juan LI, Wu MH, Shen CJ, Wu JY, Lee CC. Systematic review and meta-analysis of the diagnostic accuracy of procalcitonin, C-reactive protein and white blood cell count for suspected acute appendicitis. Br J Surg. 2013;100:322-9.
6. Paajanen H, Mansikka A, Laato M, Kettunen J, Kostiainen S. Are serum inflammatory markers age dependent in acute appendicitis? J Am Coll Surg. 1997;184(3):303-8.

7. Goodwin AT, Swift RI, Bartlett MJ, Fernando BS, Chadwick SJ. Can serum interleukin-6 levels predict the outcome of patients with right iliac fossa pain? Ann R Coll Surg Engl. 1997;79(2):130-3.

8. Yildirim O, Solak C, Koçer B, Unal B, Karabeyoğlu M, Bozkurt B, Aksaray S, Cengiz $\mathrm{O}$. The role of serum inflammatory markers in acute appendicitis and their success in preventing negative laparotomy. J Investig Surg. 2006; 19(6):345-52.

9. Türkyilmaz Z, Sönmez K, Karabulut R, Elbeğ S, Moralioğlu S, Demirtola A, et al. Sequential cytokine levels in the diagnosis of appendicitis. Scand J Clin Lab Invest. 2006:66(8):723-31.

10. Wang $Y$, Reen DJ, Puri P. Is a histologically normal appendix following emergency appendicectomy always normal? Lancet. 1996;347:1076-9.

11. Hachim MY, Ahmed AH. The role of the cytokines and cell-adhesion molecules on the immunopathology of acute appendicitis. Saudi Med J. 2006;27:1815-21.

12. Zeillemaker $A M$, Hoynck van Papendrecht $A A$, Hart MH, Roos D, Verbrugh HA, Leguit P. Peritoneal interleukin-8 in acute appendicitis. J Surg Res. 1996; 62(2):273-7.

13. Zviedre A, Engelis A, Tretjakovs P, Jurka A, Zile I, Petersons A. Role of serum cytokines in acute appendicitis and acute mesenteric lymphadenitis among children. Medicina. 2016;52(5):291-7.

14. Bhangu A, Soreide K, Di Saverio S, Assarsson JH, Drake FT. Acute appendicitis: modern understanding of pathogenesis, diagnosis, and management. Lancet. 2015;386:1278-87.

15. Yazici M, Ozkisacik S, Oztan MO, Gursoy H. Neutrophil/lymphocyte ratio in the diagnosis of childhood appendicitis. Turk J Pediatr. 2010;52:400-3.

16. Paajanen $H$, Mansikka $A$, Laato $M$, et al. Novel serum inflammatory markers in acute appendicitis. Scand J Clin Lab Invest. 2002;62(8):579-84.

17. Wu HP, Lin CY, Chang CF, et al. Predictive value of C-reactive protein at different cutoff levels in acute appendicitis. Am J Emerg Med. 2005;23(4): 449-53.

18. Nathan C. Neutrophils and immunity: challenges and opportunities. Nat Rev Immunol. 2006:6:173-82.

19. Lee SL, Ho HS. Acute appendicitis: is there a differencebetween children and adults? Am Surg. 2006:72:409-13.

20. Stankovic N, Djordjevic D, Rondovic G, Kostic Z, Zeba S, Milosavljevic S, et al. Neutrophil myeloperoxidase index in pediatric acute appendicitis. Vojnosanit Pregl. https://doi.org/10.2298/NSP171218012S.

21. Stankovic N, Stanojevic I, Djordjevic D, Kostic Z, Udovicic I, Milickovic M. At al. Neutrophil-to-lymphocyte ratio in pediatric acute appendicitis. Vojnosanit Pregl. 2018;75(1):46-55.

22. Hoffbrand AV, Moss PAH. Pettit JE. Essential Haematology Oxford: Blackwell; 2006. p. 94-103.

23. Jahangiri M, Wyllie JH. Peripheral blood lymphopenia in gangrenous appendicitis. BMJ. 1990;301:215

24. Kharbanda AB, Rai AJ, Cosme Y, Liu K, Dayan PS. Novel serum and urine markers for pediatric appendicitis. Acad Emerg Med. 2012;19(1):56-62.

25. Sack U, Biereder B, Elouahidi T, Bauer K, Keller T, Tröbs RB. Diagnostic value of blood inflammatory markers for detection of acute appendicitis in children. BMC Surg. 2006:6:15.

26. Rivera-Chavez FA, Wheeler H, Lindberg G, Munford RS, O'Keefe GE. Regional and systemic cytokine responses to acute inflammation of the vermiform appendix. Ann Surg. 2003;237:408-16.

27. Yoon DY, Chu J, Chandler C, Hiyama S, Thompson JE, Hines OJ. Human cytokine levels in nonperforated versus perforated appendicitis: molecular serum markers for extent of disease? Am Surg. 2002;68:1033-7.

28. Eriksson S, Granström L, Olander B, Wretlind B. Sensitivity of interleukin-6 and $\mathrm{C}$-reactive protein concentrations in the diagnosis of acute appendicitis. Eur J Surg. 1995;161(1):41-5.

29. Eriksson S, Granstroöm L, Bark S. Laboratory tests in patients with suspected acute appendicitis. Acta Chir Scand. 1989:155:117-20.

30. Waal MR, Abrams J. Interleukin-10 inhibits cytokines synthesis by human monocytes: an auto regulatory role of IL-10 produced by monocytes. J Exp Med. 1991;174:1209-020

31. Couper KN, Blount DG, Riley EM. IL-10: the master regulator of immunity to infection. J Immunol. 2008;180:5771-7.

32. Cook DN. The role of MIP-1 alpha in inflammation and hematopoiesis. J Leukoc Biol. 1996;59(1):61-6. 
33. Liu M, Guo S, Stiles JK. The emerging role of CXCL10 in cancer (review). Oncol Lett. 2011;2(4):583-9.

34. Fujii H, Shimada Y, Hasegawa M, Takehara K, Sato S. Serum levels of a Th1 chemoattractant IP-10 and Th2 chemoattractants, TARC and MDC, are elevated in patients with systemic sclerosis. J Dermatol Sci. 2004;35(1):43-51.

35. Falconer K, Askarieh G, Weis N, Hellstrand K, Alaeus A, Lagging M. IP-10 predicts the first phase decline of HCV RNA and overall viral response to therapy in patients co-infected with chronic hepatitis $C$ virus infection and HIV. Scand J Infect Dis. 2010;42:896-901.

36. Pourhabibi Zarandi N, Javidi Parsijani P, Bolandparvaz S, Paydar S, Abbasi H. Accuracy of Surgeon's Intraoperation diagnosis of acute appendicitis, compared with the histopathology results. Bulletin of Emergency \& Trauma. 2014;2(1):15-21.

37. Flum DR, Koepsell T. The clinical and economic correlates of misdiagnosed appendicitis: nationwide analysis. Arch Surg. 2002;137(7):799-804.

38. Kryzauskas M, Danys D, Poskus $T$ at al. Is acute appendicitis still misdiagnosed? Open Med. 2016;11(1):231-6.

39. Eriksson S, Olander B, Pira U, Granström L. White blood cell count, leucocyte elastase activity, and serum concentrations of interleukin-6 and C-reactive protein after open appendicectomy. Eur J Surg. 1997;163(2):123-7.

40. Rubér M, Berg A, Ekerfelt C, Olaison G, Andersson RE. Different cytokine profiles in patients with a history of gangrenous or phlegmonous appendicitis. Clin Exp Immunol. 2006;143(1):117-24.

41. Dalal I, Somekh E, Bilker-Reich A, Boaz M, Gorenstein A, Serour F. Serum and peritoneal inflammatory mediators in children with suspected acute appendicitis. Arch Surg. 2005:140:169-73.

42. Rezende-Neto JB, Moore EE, Melo de Andrade MV, Teixeira MM, Lisboa FA, Arantes RM, et al. Systemic inflammatory response secondary to abdominal compartment syndrome: stage for multiple organ failure. J Trauma. 2002; 53(6):1121-8.

43. von Elten KA, Duran LL, Banks TA, Banks TA, Collins LC, Collins LC. Systemic inflammatory reaction after pneumococcal vaccine: a case series. Hum Vaccin Immunother. 2014:10(6):1767-70.

44. Lord JM, Midwinter MJ, Chen Y-F, Belli A, Brohi K, Kovacs EJ, et al. The systemic immune response to trauma: an overview of pathophysiology and treatment. Lancet. 2014;384(9952):1455-65.

45. van Dissel JT, van Langevelde P, Westendorp RG, et al. Anti-inflammatory cytokine profile and mortality in febrile patients. Lancet. 1998;351:950-3.

46. Gogos CA, Drosou E, Bassaris HP, et al. Pro- versus anti-inflammatory cytokine profile in patients with severe sepsis: a marker for prognosis and future therapeutic options. J Infect Dis. 2000;181:176-80.

47. Sfeir T, Saha DC, Astiz M, et al. Role of interleukin-10 in monocyte hyporesponsiveness associated with septic shock. Crit Care Med. 2001;29:129-33.

48. Munford RS, Pugin J. Normal responses to injury prevent systemic inflammation and can be immunosuppressive. Am J Respir Crit Care Med. 2001:163:316-21.

\section{Publisher's Note}

Springer Nature remains neutral with regard to jurisdictional claims in published maps and institutional affiliations.

Ready to submit your research? Choose BMC and benefit from:

- fast, convenient online submission

- thorough peer review by experienced researchers in your field

- rapid publication on acceptance

- support for research data, including large and complex data types

- gold Open Access which fosters wider collaboration and increased citations

- maximum visibility for your research: over $100 \mathrm{M}$ website views per year

At $\mathrm{BMC}$, research is always in progress.

Learn more biomedcentral.com/submissions 